\title{
Topoclimate in Morlet, Cross and Coherence Wavelet Analyses in the Brazilian Cerrado
}

\author{
Ângela Fátima da Rocha1 (D) Ernany Paranaguá da Silva ${ }^{2}$ (D), \\ Carlo Ralph De Musis ${ }^{3}$ (D) \\ ${ }^{1}$ Departamento e Área de Construção Civil - DACC, Instituto Federal de Educacão, Ciência e Tecnologia \\ de Mato Grosso-IFMT, Cuiabá, MT, Brasil \\ ${ }^{2}$ Departamento da Área de Eletro-Eletrônica - DAEE, Instituto Federal de Educacão, \\ Ciência e Tecnologia de Mato Grosso-IFMT, Cuiabá, MT, Brasil \\ ${ }^{3}$ Programa de Pós-Graduação em Ciência Ambiental, Universidade de Cuiaba-UNIC, Cuiabá, MT, Brasil
}

\begin{abstract}
In recent years, the Traditional Morlet Transform, Cross and Wavelet Coherence have been used as techniques to analyze time series from meteorological and climatic data, obtaining useful information. These techniques were used to study air temperature and relative air humidity, air pressure and wind variables from 2015 to 2017. The data was collected from a micrometeorological station of the Federal University of Mato Grosso State. The objective of the study was to obtain information regarding seasonal trends and effects. The Coherence constituted the normalized spectrum of the TWX, smoothed in time and scale. The seasonality of the region is characterized by the existence of two annual seasons, hot-humid and hot-dry seasons, qualitatively determining the energy levels of the urban cerrado ecosystem.
\end{abstract}

Keywords: micrometeorological variables, power spectrum, urban climate. 


\section{INTRODUCTION}

The climate is an example of a system that can be characterized as complex, subject to interference from different natural and human variables, which are responsible for its linearity or not, and its dynamics. Therefore, working with phenomena connected with the climate and weather means thinking in possibilities rather than absolute certainties; because climatic changes are a fertile topic for scientific discussion and allow several studies regarding their causes, effects, and consequences.

Air temperature and relative air humidity in the urban environment involve different spatio-temporal scales, using statistical analyses that provide an understanding of repetitive patterns necessary for their comprehension. Therefore, analyses of time series using Wavelet Transformers allow us to identify behavioral patterns in different time, scale and energy intensity dimensions as a qualitative tool at the service of urban dynamics (Torrence \& Compo, 1998), (Feng \& Liang, 2016).

The Wavelet Transform reveals which part of the signal analyzed transports significant energy over time and at which frequencies (scales) this occurs. To verify similarity between two signals, the Crossed Wavelet Spectrum TWX, which is characterized by the module and by the Traditional Wavelet Transform TWC as well as the Coherence Wavelet, make up the normalized spectrum of the TWX, smoothed in time and scale, (Addison, 2017; Domingues et al., 2016; Torrence \& Webster, 1999).

The Brazilian central east area has one of the hottest cities in Brazil and, its urban growth processes should receive special attention due to belonging to the cerrado ecosystem. The cerrado is a threatened biome and the survival of its species depends on conservation and preservation, mainly considering urban expansion. Knowledge of the dynamics of relative air temperature and of the surface temperatures of the city, as well as their interaction with relative air humidity, wind, atmospheric air pressure and precipitation, together with processes of absorption, irradiation and reflection in cities, are a complex problem for analysis, requiring multi-scale analyses.

In this context, the aim of the study was to analyze the behavior of an urban topoclimate in the cerrado using the microclimate variables of air temperature and relative air humidity, wind, and atmospheric air pressure, using the Morlet Wavelet Transform, Crossed and Wavelet Coherence.

\section{MATERIAL AND METHODS}

The city of Cuiabá, capital of the state of Mato Grosso, with coordinates of $15^{\circ} 35^{\prime} \mathrm{S}$ and $56^{\circ} 06^{\prime} \mathrm{E}$, altitude of $165 \mathrm{~m}$, is located in the region named as "Cuiaban depression". It has an area of $3,224.68 \mathrm{~km}^{2}$ with $254,57 \mathrm{~km}^{2}$ being urban area and $2,970.11 \mathrm{~km}^{2}$ being rural area. It is situated in a region where three important Brazilian ecosystems meet, the cerrado surrounding it, the Pantanal to the south and the Amazon rainforest to the north. The predominant vegetation is cerrado, with the denser forests being found nearer to the water courses, (Cuiabá, 2012).

According to the Köppen classification, the regional climate is Aw, which represents a semi-humid tropical climate, with two well defined seasons, one dry (Autumn-winter) and one rainy (spring-summer). The average annual air temperature is between 25 and $26{ }^{\circ} \mathrm{C}$, while the maximum air temperature frequently exceed $35^{\circ} \mathrm{C}$ throughout nearly the whole year. The average annual maximum air temperature in Cuiabá varies from 31 to $34^{\circ} \mathrm{C}$. The average annual minimum air temperature varies between 18 to $21{ }^{\circ} \mathrm{C}$. While the relative air humidity has an annual average of $70 \%$, the relative air humidity drops in the winter, reaching levels of $12 \%$, being the dry season period. Accumulated average annual precipitation is $1500 \mathrm{~mm}$ /year. Wind direction is predominantly $\mathrm{N}$ (north) and NE (northeast) during a large part of the year, and S (south) during the winter. Cuiabá is located in a geographical depression which means that the average wind frequency and velocity are extremely low, minimizing the effect of thermal exchange by convection and underlining further still the influence of constructed spaces on air temperature.

This study was done at the topoclimate scale, with the scale level corresponding to a derivation of the local climate due to the ruggedness of the terrain, that is, receiving a solar radiation unevenly throughout the day, Oke (2006). During the night, the ruggedness of the terrain led the cold air toward the bottom of the valley. The time of action of the climate influenced by 
the topography was no more than 24 hours, and the spatial level was restricted by the form of the relief, varying from 0.5 to $5 \mathrm{~km}$. Microclimates have the effects of the urban action on these same climates, and the effects of these modifications on the built environment. Figure 1 shows the region of influence of the topoclimate studied.

Cuiabá has the highest air temperatures in August, September and October, and minimum temperatures in May, June, and July.

Air temperature and relative air humidity data was measured at a Davis Instruments micrometeorology station of the Post-Graduate program in Environmental Physics at the campus of the Federal University of Mato Grosso State, in Microclimate Analysis and Modelling of Urban Systems research. It is situated at $15^{\circ} 36^{\prime} \mathrm{S}$ and $56^{\circ} 06^{\prime} \mathrm{E}$, at $157 \mathrm{~m}$ altitude, in eastern Cuiabá, with the station being installed in a construction for institutional use, located near to the Cuiabá River. Hourly, daily, monthly and annual analyses were performed, during 2015, 2106 and 2017.

Air temperature and relative air humidity data was compiled in tables and inserted as entry data using two algorithms, one of them according to Torrence \& Compo (1998) and the other according to Jevrejeva et al. (2003). The Morlet non orthogonal Wavelet complex was used and defined by Equation 1, in which, $\psi$ is the value of the wavelet for a non-adimensional parameter, $\boldsymbol{w}_{0}$ is the frequency and provides the oscillations within the wavelet itself and $\mathbf{t}$ is the period or the time scale of analysis.

$\psi(t)=\pi^{-0,25} e^{-i w_{0} t} e^{-1 / 2 t^{2}}$, to $\quad w_{0} \geq 5$

The wavelet transform and the Morlet Wavelet are efficient to handle microclimatic variables, the former for being able to decompose another function into

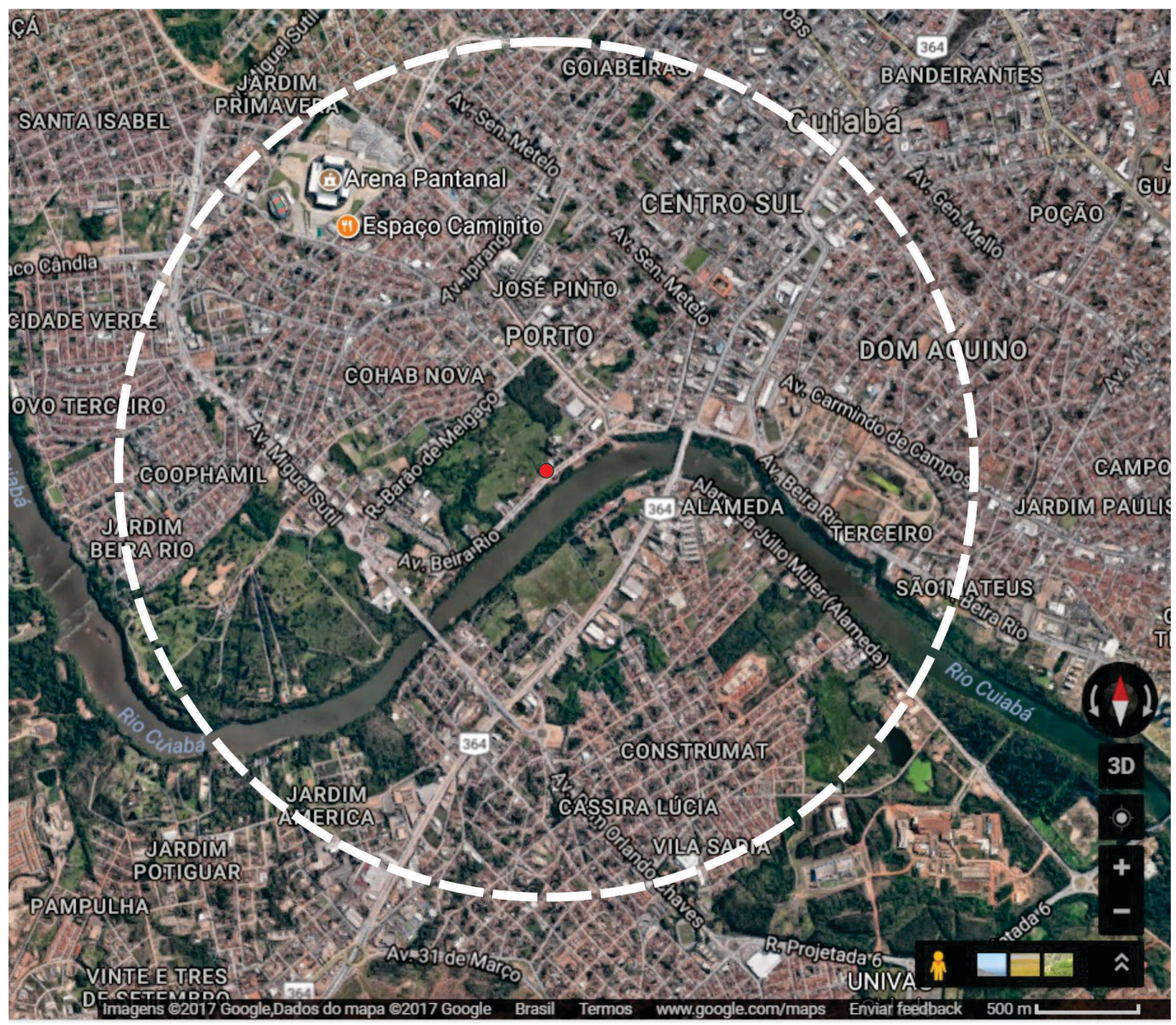

Figure 1. Region of study - Google Earth Pro - $15^{\circ} 36^{\prime} \mathrm{S}$ and $56^{\circ} 06^{\prime} \mathrm{O}$. 
different frequency and time scales, and the latter for having low oscillation in the extraction of characteristics.

Wavelets have mobile windows in time and space that expand or contract to capture low and high-frequency signals, which helps in the analysis of the microclimatic variables adopted (Ehlers, 2009). According to Vilani $\&$ Sanches (2013), Addison (2017) $\boldsymbol{w}_{0}=6$ was adopted to satisfy the condition of admissibility, meaning that, for this value, the errors due to measurement not equal to zero, are less than the typical rounding errors (Domingues et al., 2016).

The Crossed Wavelet Spectrum TWX was used to examine the relationship and similarity between two signals, following Grinsted et al. (2004), characterized by the module and by the phase of the Traditional Wavelet Transform TWC.

According to Torrence \& Webster (1999), the TWX were generated, from the air temperature series, $\mathrm{X}(\mathrm{t})$ and from the relative air humidity, $\mathrm{Y}(\mathrm{t})$ for example, with the respective transformers $\mathrm{Wx}(\mathrm{s}, \mathrm{t})$ and $\mathrm{Wy}(\mathrm{s}, \mathrm{t})$ with their conjugates $\left({ }^{*}\right)$, where " $\mathrm{s}$ " is the scale and " $\mathrm{t}$ " the time. Their product is presented using Equation 2.

$$
X W_{f, g}(a, b)=W_{f}^{*}(a, b) W_{g}(a, b)
$$

The term $\mathrm{XW}_{\mathrm{f}, \mathrm{g}}(\mathrm{a}, \mathrm{b})$ from Equation 2 expresses the product of the coefficients of the Wavelet Transform at a given scale " $a$ " in the neighborhood $(t=b)$, where the energy spectra are crossed, and the two series tested and exposed to verification regarding their phase or anti-phase relationship in the time-frequency space. The power of the TWX is the energy from the bottom of the spectrum, where the level of confidence was 95\%.

The Wavelet Coherence constituted the normalized spectrum of the TWX, smoothed in time and in the scale. The coefficients of the Crossed Spectrum Wavelet reveals when there is an elevated degree of correlation between $f(t)$ and $g(t)$. Equation 3 shows the factor $\left(\mathrm{s}^{-1}\right)$ used to normalize the energy density, and (s) is the smoothing operator in the time and scale used.

$$
W C_{f, g}(a, b)=\frac{\mid s\left(\left.s^{-1} x w_{f, g}(a, b)\right|^{2}\right.}{s\left(s^{-1}\left|w_{f}(a, b)\right|^{2}\right) s\left(s^{-1}\left|w_{g}(a, b)\right|^{2}\right)}
$$

The correlation between the two signals is provided according Misiti et al. (2017) as a function of time and frequency. Being a measure of association between the two air temperature and relative air humidity series, it allows the visualization of coincident events over the scales and frequencies at each instant of time of the signals of the series.

Monte Carlo Tests are performed using the algorithm for verification at the level of significance of $95 \%$ for the Gaussian white noise filters. The edge effects are considered according to the cone of influence (COI) inserted into the scales of TWC, TWX, and CW.

According to Domingues et al. (2016) other classic methods of "crossed correlation" for example, can be used to determine the coherent structures of two signals only for their time delay; however, it fail when there are multiple periods. Therefore, observations of the crossed wavelet correlations are needed, by generating symetrical coefficients in relation to " $b$ "; and belonging to the interval $[-1,1]$. The "correlation by scale" method can also be used to study the relationship between different scales of two signals $f$ and $g$ analyzed in the domain of the wavelet. This correlation is verified using the algorithms with the different types of signals. Therefore, it allows the results of the crossed spectrum to indicate results that can be verified as true in the significance tests for inter-relationship between two temporal series, which allows the analysis of the results, and of the analyses of the TWC, TWX, and CW.

The data was presented in with the aim of not modifying its originality in verifying periodicity.

In this study, the algorithms used were from C. Torrence, available at http://paos.colorado.edu/research/wavelets, accessed on $27^{\text {th }}$ of Oct. 2016, and from Grinsted, J.C. available at http://noc.ac.uk/using-science/crosswavelet-waveletcoherence accessed on $27^{\text {th }}$ of Oct., 2016.

\section{RESULTS AND DISCUSSION}

Brazilian ecosystems under go global climatic events. Also, there are efforts to contain the extreme disturbances in the Amazon ecosystem, for example. However, for the Cerrado ecosystem, these efforts are almost nonexistent.

The results of the research in the Mato Grosso urban cerrado follow, where the wavelet analysis within the context in which it was applied was found to be a useful tool. Two dry seasons and a rainy season were analyzed between 2015 and 2016. 
Starting from the $23^{\text {rd }}$ of April, 2015 to the $22^{\text {nd }}$ of September, 2015, dry season, the higher monthly temperature and relative air humidity averages were in September $\left(30.7^{\circ} \mathrm{C} \pm 3.7^{\circ} \mathrm{C}\right)$ and April $(82.0 \% \pm 6.9 \%)$ respectively; the lower monthly averages in July $\left(25.5^{\circ} \mathrm{C} \pm 3.3{ }^{\circ} \mathrm{C}\right)$ and August (47.6\% $\left.\pm 8.2 \%\right)$; with thermal amplitude of $5.2^{\circ} \mathrm{C}$ for the air temperature and $34.4 \%$ for humidity. Considering the season of the year -autumn- the daily maximum and minimum for air temperature, that is, the hottest and the coldest days, were $\left(29.3^{\circ} \mathrm{C} \pm 3.3^{\circ} \mathrm{C}\right.$ and $\left.18.0^{\circ} \mathrm{C} \pm 1.0^{\circ} \mathrm{C}\right)$ respectively; as well as, the most humid and driest days, with relative air humidity $(95.1 \% \pm 7.9 \%$ and $63.7 \% \pm 14.8 \%)$; for the season -winter- the hottest and the coldest days $\left(34.4{ }^{\circ} \mathrm{C} \pm 4.1{ }^{\circ} \mathrm{C}\right.$ and $17.1{ }^{\circ} \mathrm{C} \pm 1.1{ }^{\circ} \mathrm{C}$ ) and the most humid and driest days were obtained $(90.4 \% \% \pm 7.6 \%$ and $31.0 \% \pm 9.7 \%$ ).

From the $23^{\text {rd }}$ of September, 2015 to the $21^{\text {st }}$ of March 2016, rainy season, the higher monthly averages for air temperature and relative air humidity were in October $\left(29.8^{\circ} \mathrm{C} \pm 3.8^{\circ} \mathrm{C}\right)$ and January $(83.0 \% \pm 7.6 \%)$; the lower monthly averages were in January $\left(27.5^{\circ} \mathrm{C} \pm 1.6^{\circ} \mathrm{C}\right)$ and October $(64.4 \% \pm 12.8 \%)$ respectively; with a thermal amplitude of $2.3^{\circ} \mathrm{C}$ for the temperature of $18.6 \%$ for humidity. Considering the season of the year (spring), the daily maximum and minimum for relative air temperature, that is, the hottest and coldest days were $34.9^{\circ} \mathrm{C} \pm 4.1^{\circ} \mathrm{C}$ and $19.8^{\circ} \mathrm{C} \pm 1.6^{\circ} \mathrm{C}$ respectively; as well as, the most humid and the driest days, with relative air humidity were $88.2 \% \pm 2.7 \%$ and $42.0 \% \pm 12.1 \%$; for the season -summer-, the hottest and coldest days obtained were $31.6{ }^{\circ} \mathrm{C} \pm 3.7^{\circ} \mathrm{C}$ and $25.0{ }^{\circ} \mathrm{C} \pm 1.5^{\circ} \mathrm{C}$ and the most humid and driest were $93.2 \% \pm 6.5 \%$ and $63.3 \% \pm 14.5 \%$.

Starting from the $22^{\text {nd }}$ of March 2016 to the $21^{\text {st }}$ of September 2016, once again in the dry season (autumn-winter), the higher monthly averages for air temperature and relative air humidity occurred in April $\left(28.0^{\circ} \mathrm{C} \pm 4.3^{\circ} \mathrm{C}\right)$ and May $(79.7 \% \pm 8.0 \%)$ respectively; the lower monthly averages in June $\left(23.4^{\circ} \mathrm{C} \pm 3.5^{\circ} \mathrm{C}\right)$ and July $(57.0 \% \pm 9.4 \%)$; with thermal amplitude of $4.6^{\circ} \mathrm{C}$ for temperature and $22.7 \%$ for humidity. Considering the season of the year (autumn) the daily maximum and minimum for air temperature, that is, the hottest and coldest days were $31.3{ }^{\circ} \mathrm{C} \pm 3.7{ }^{\circ} \mathrm{C}$ and $15.4^{\circ} \mathrm{C} \pm 0.4^{\circ} \mathrm{C}$ respectively; as well as, the most humid and driest days, with relative air humidity of $92.7 \% \pm 4.9 \%$ and $59.5 \% \pm 13.1 \%$; for the season (winter), the hottest and coldest dayswere $32.4{ }^{\circ} \mathrm{C} \pm 4.8^{\circ} \mathrm{C}$ and $13.5^{\circ} \mathrm{C} \pm 0.7{ }^{\circ} \mathrm{C}$ and the most humid and driest days were $94.6 \% \pm 3.9 \%$ and $38.9 \% \pm 16.2 \%$.

The characteristics were hot, dry climate for autumn-winter, with daily air temperature and relative air humidity averages of $27.6{ }^{\circ} \mathrm{C} \pm 3.1{ }^{\circ} \mathrm{C}$ and $65.2 \% \pm 16.3 \%$ for the dry period respectively; however, for spring-summer season, the hot climate continues but more humid. The daily air temperature and relative air humidity averages for the rainy season were $28.9^{\circ} \mathrm{C} \pm 2.3^{\circ} \mathrm{C}$ and $73.6 \% \pm 10.9 \%$ respectively. This behavior is common to the cerrado region.

Because it is one of the hottest capitals in Brazil, the importance of the influence of the constructed urban space on air temperature as well as the consequences of the hot climate on urban cerrado environments are highlighted. Also, despite the daily averages not presenting extreme values during the dry season, at the hottest hours of the day between 1 p.m. and 2 p.m., the maximum air temperature reached was $41.5^{\circ} \mathrm{C} \pm 0.6^{\circ} \mathrm{C}$ together with $18.6 \% \pm 0.5 \%$ for relative air humidity. Considering the low relative air humidity, the thermal amplitude for some days provokes alarming levels of thermal discomfort, leading to several human health problems. Even having the title of green city, due to a proportion of green area of nearly 3:1 (tree/inhabitant), the cerrado climate of the Brazilian Central-West also stands out on some days for low air temperature with or without lows in relative air humidity, with the so-called "Cuiaban winter" being practically on these days. In these extreme and uncomfortable conditions, studies of the microclimatic spaces and the topoclimate are justified.

The air temperature and relative air humidity variables were normal, with Kolmogorov-Smirnovs tests that rejected the non-normality hypothesis, and homoscedastic distributions. The central trend measures, the mean and the median showed almost no divergence. For the amplitude analyses, the asymmetry for relative air temperature was slightly positive; for relative air humidity the asymmetry was slightly to the right, and toward kurtosis for air temperature and relative air humidity. This indicated slight flattening for the distribution peak for the Gaussian distribution, demonstrating a mesokurtic distribution in the two situations. This highlighted a density function of proximity near to Normal, confirmed by the Kolmogorov-Smirnov 
test $(\mathrm{p}>5 \%)$, therefore, within the conditions for the wavelet analyses.

The exploratory analysis for the wind and atmospheric air pressure variables indicated that according to the Kolmogorov-Smirnov tests, the statistical parameters did not apply to the two data series. In this case, the confidence intervals were calculated by bootstrap. The presence of trends was validated by the non-parametric Mann-Whitney test since random and complex environmental data is being studied. The wavelet analyses came from samples with readings every five minutes. Figure 2 (a) allowed the visualization of the magnitudes of the variability of the original time series over time respectively; and Figure 3(b) presents the median variability over time and above the dotted line the white noise model with $95 \%$ reliability.

From $23^{\text {rd }}$ of April, 2015, autumn-winter, characterized as dry season, followed by spring-summer, as the rainy season, and concluding on $25^{\text {th }}$ of July 2016 , once again during the dry period, for the air temperature and relative
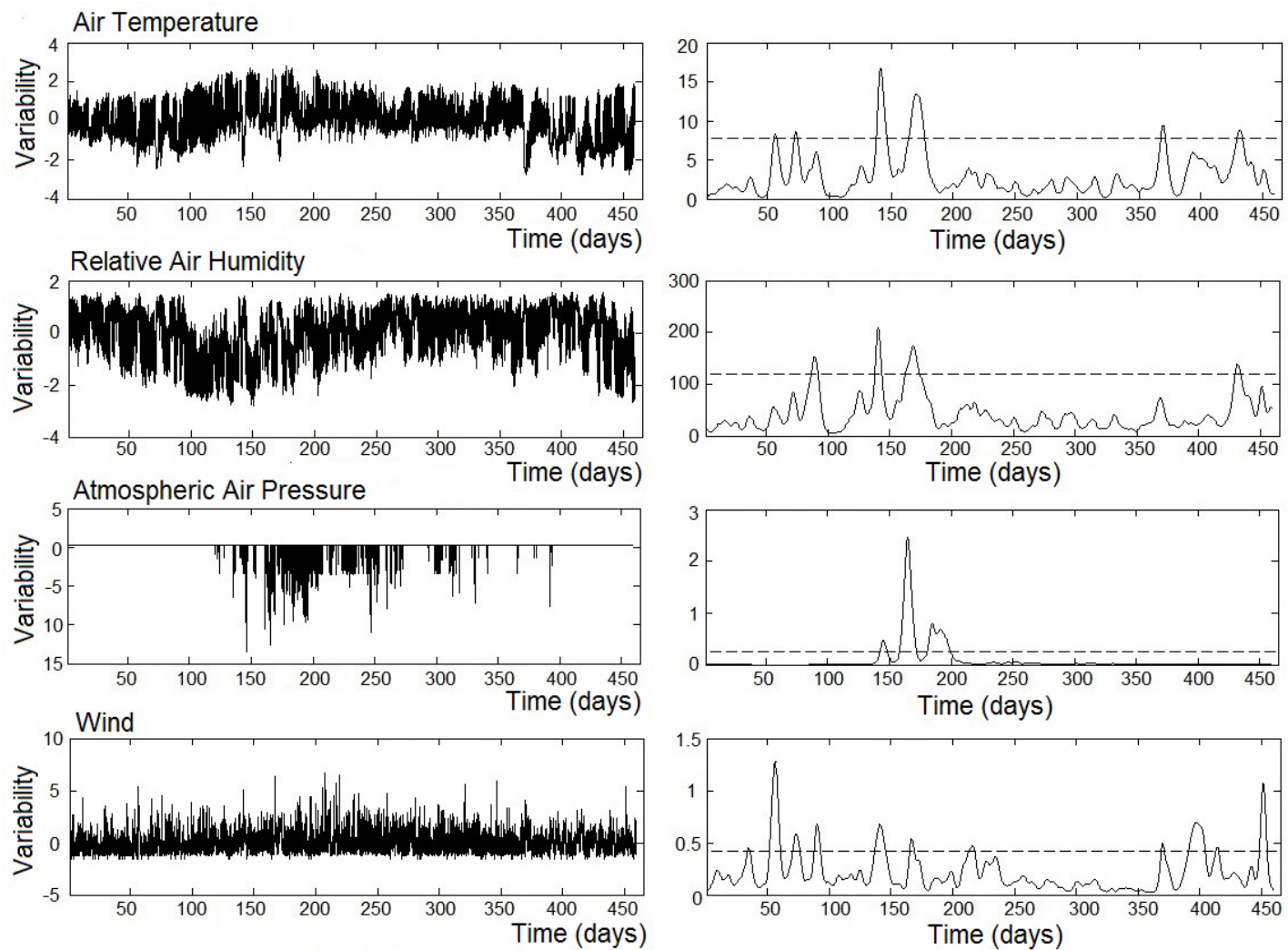

(a)

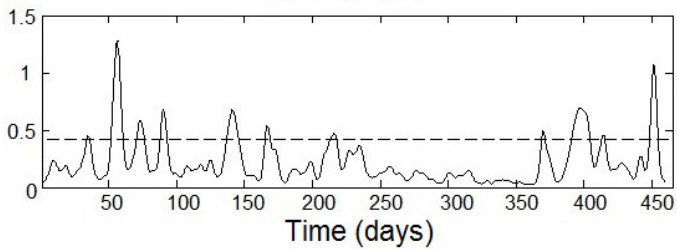

( b )

Figure 2. (a) Variability of the collected variables and (b) mean annual variance of the variables. 


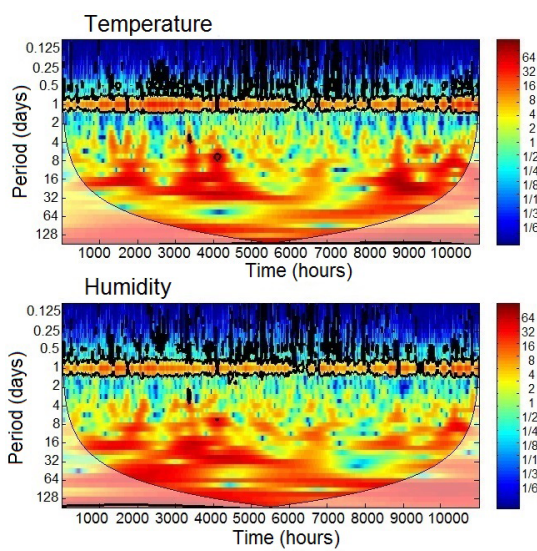

(a)

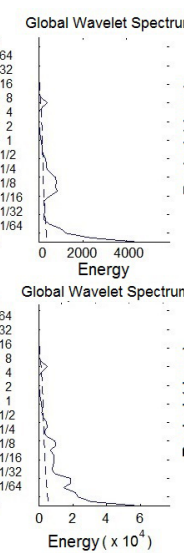

Energy $\left(\times 10^{4}\right)$

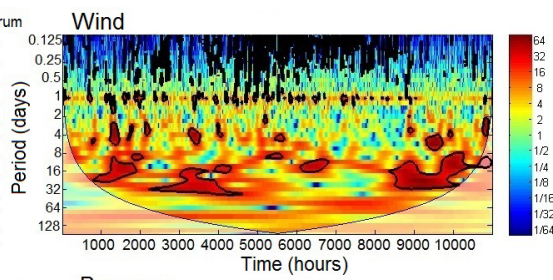
Pressure

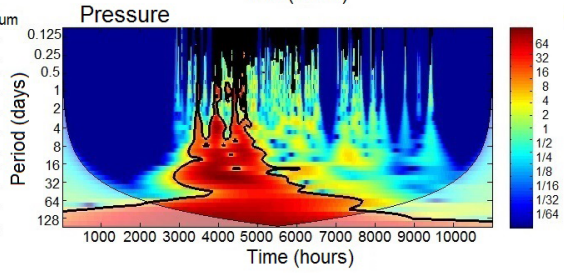

(b)
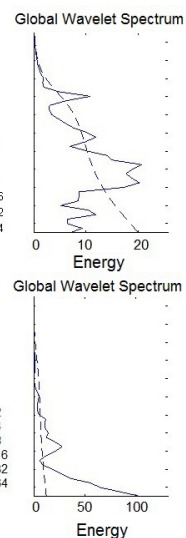

Energy

Figure 3. (a) Annual traditional TWC for air temperature and humidity and (b) Annual TWC for wind and atmospheric air pressure.

The modules of these coefficients show the amplitude of the signal, and the energy provided is its density. Together with this, the Global Power Spectrogram EPG is the graph for global variance interpreted as the contribution of energy of scale to the total energy of the Morlet function in relation to time. The color palette used has a logarithmic distribution, and the significance of the amplitudes of the coefficients found using the TWC verify the spectrum edges, where the so called cone of influence COI defines the spectrum decay in each scale; the level of significance of $95 \%$ for the background red noise for areas circled by red color in the time domain, found for the wind variable and in the periods of variation for atmospheric air pressure.

The TWC's shown in Figure 3, for air temperature and relative air humidity Figure (3a) and wind and atmospheric air pressure Figure (3b), demonstrate periodicity of 24 hours (daily cycle) according to the rotating movement of the planet, with a light peak in the high frequency for air temperature and relative air humidity in its global spectrograms EPG, represented by the red and orange colors in the scale diagram. For the wind variable, the periodicity of the daily cycle is not effectively uniform throughout the year, despite having a high-frequency peak in the power spectrum EPG. Periodicity of 4, 8 and 16 days at high frequency in red, in time domains of 1000 and 2000 hours, and 3000 and 4500 hours, belonging to the dry season for the three variables, for the relative air humidity variable and in some points for the wind variable, there was also a periodicity of 32 days at high power for 4500 hours to 6500 hours. For the rainy season, there was practically no periodicity coincident with the TWC of the variables, where the variability of the latent heat of the water vapor did not allow dominant periodicity of air temperature. However, the tropical seasonality of the cerrado was strongly marked by the variables. The delay relationship between the air temperature and relative air humidity variables are highlighted, demonstrating the inversibility that exists between them.

Except for the atmospheric air pressure variable, periodicity of 4 to 64 days in a time domain of 8000 to 10000 hours at high power for the dry season subsequent to the rainy season are in red and dark red, with power spectra in low and high-frequency EPG. Using Figure 2(b), it was found that the increase in red noise in the series occurred in the same time domains identified in the scale diagrams of the TWC.

In the TWX's from Figure 4, there were areas detected in the time domain using the interrelations between the variables, where the phase is the measure of the difference between the four signals analyzed. To test the significance of the interrelations, the $\mathrm{CW}$ was subsequently applied.

Therefore: - TWX of air temperature and relative air humidity: confirm the 24-hour periodicity (daily) throughout the period studied, the variables are in anti-phase (indicating arrows from right to left for periodicity in the daily cycle), and there are areas of 
significance of 95\% (circled in black), but every area in red is indicative of elevated significance levels.

TWX of air temperature and wind: confirms the daily periodicity between the variables, being in intermediary situations between phase and anti-phase (arrows indicating the different delays between the variables) for the daily cycle, various areas in red circled in black, significant in the scale diagram. It is important to highlight the similarity of the spectrum densities between TWX of air temperature and relative air humidity, TWX of air
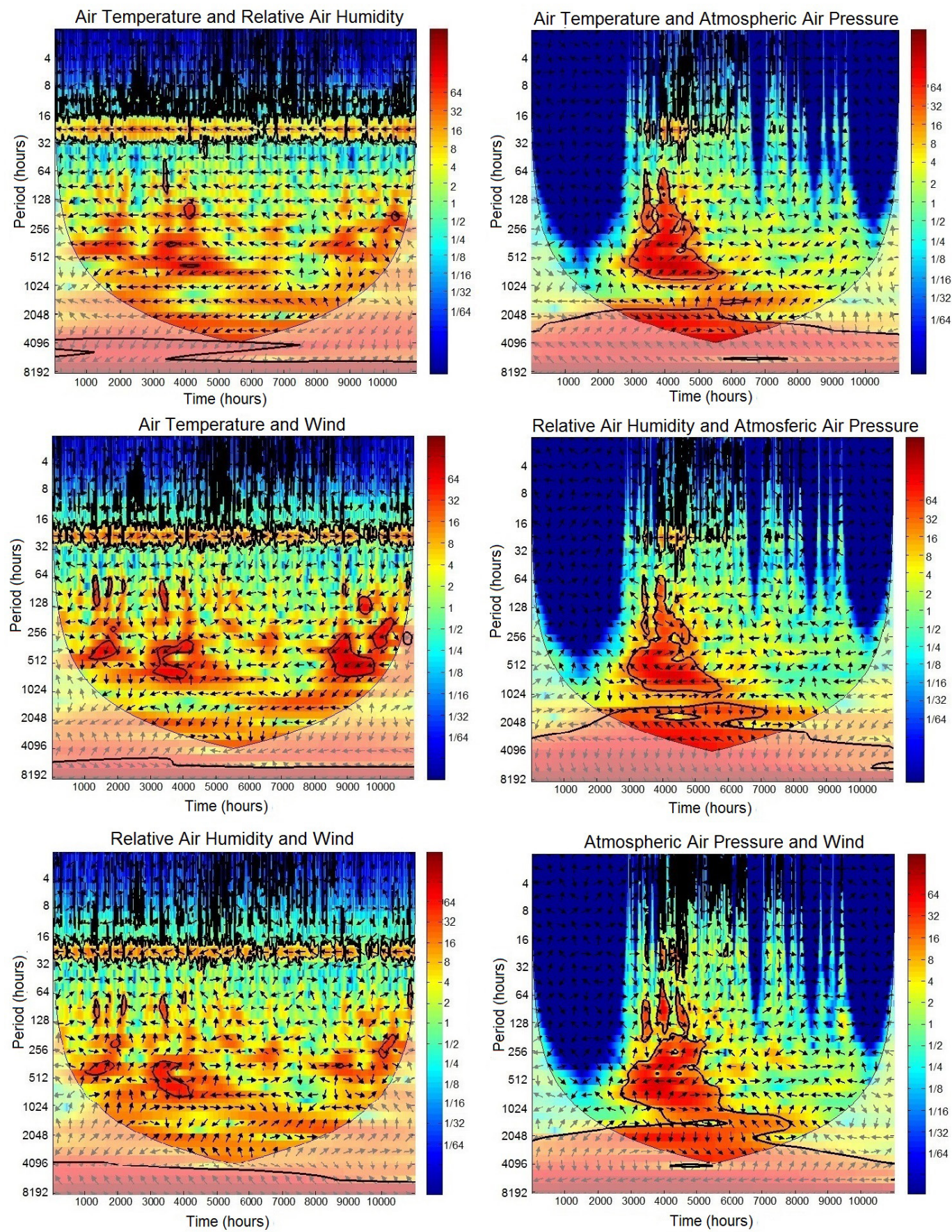

Figure 4. TWX of the temperature and humidity variables of air, wind and atmospheric pressure. 
temperature and wind and TWX of humidity and wind, indicative of the inter-relationship between the three variables.

TWX of air temperature and atmospheric air pressure: perception of the daily cycle, indicative of the anti-phase variables; in the period captured of inter-relationship with significance of $95 \%$ between the variables starting from 64 to 768 hours or from 3 to 32 days, with a time domain of 3000 to 5500 hours; periodicity of 128 days with $95 \%$ significance for 3000 to 7500 hours; blue conical areas indicate atmospheric air pressure without variation in the respective periods, probably due to being in a region of depression, where reliefs with low altitudes predominate varying density between 146 to 259 meters in urban areas;

- TWX of wind and atmospheric air pressure: background spectrum with 95\% significance between the variables, with slightly signaled periodicity in the region of daily cycle to 4000 hours of the time domain, with different delays; having blue conical formation as previously indicated;

- TWX of relative air humidity and wind: reaffirming behavior between TWX's of temperature and wind, and humidity and wind, with air temperature and relative air humidity;

- TWX of relative air humidity and atmospheric air pressure: confirming behavior between TWX's of temperature and pressure, and wind and pressure, as described above.

All the six TWX's show the interrelations between the four variables. The wavelet tools corroborate with the question of a variable explaining the variation of the other variable.

In rural areas, the latent heat flow provides the major portion. However, the flow of sensitive heat in the cities provides the major contribution, since depletion of the anthropogenic heat from the urban surfaces and the concentrations of aerosols, together with the urban nebulosity, generates the radiation and energy balances, completing the urban dynamic in a more assertive manner (Peng et al., 2016).

The Wavelet Coherence CW coefficients are also shown in the scale diagrams (color map) for the four original signals. The horizontal axis represents the time domain and the vertical axis represents the scales used to do the Coherence calculation. If the signals have the same frequencies and the same amplitudes, that is, if they are practically equal, the degree of correlation between them will be high, that is, close to 1 . This fact is noticed through the intensity of the colors of the coefficients in the scale diagrams. Therefore, the Wavelet Coherence presents values between 0 (zero) and 1 (one). For the values close to 1 (one) the correlation is high and the represented color is dark red. For values close to 0 (zero), the correlation is low, and the color that represents it is dark blue. The colors light blue, green, yellow and orange make up the intermediary values. All the areas in dark red were grouped by Monte Carlo test with level of confidence of $95 \%$ for the Gaussian white noise model.

Figure 5 presents the CW with the test at 95\% significance between the inter-relationships of the time series through the Monte Carlo test, (Frick et al., 1998), and (Geissbuehler \& Lasser, 2013). Therefore:

-CW of air temperature and relative air humidity: qualitatively the dark red in the scale diagram represents the verification of the inter-relationship captured by the TWX between the TWC's of temperature and humidity. This is signaled not only for the daily cycle but for all the background spectra of the TWX, affirming behavior in the anti-phase between variables (indicating arrows pointing from the left to right); as well as seasonality between dry and rainy periods;

- air temperature and wind CW's, and for relative air humidity and wind: with scale diagrams that represent the inter-relationships between the variables in dark red and circled in black at different points of the spectrum for the periodicities found in the respective TWX's. The three variables once again show their interrelated behaviors;

-CW's for air temperature and relative air humidity and atmospheric air pressure, and wind and atmospheric air pressure: confirmed the coherence in a reduced number of areas of the spectra, but still guarantee the inter-relationship between 64 and 128 hours, and further still at 512 hours, in time domains of 2500 to 9000 hours.

For the Kinetic Theory of Gases, when one ideal gas goes from an initial state to a final temperature and volume state, the variation of existent entropy is real. The measure of the temperature of a gas, for example, the water vapor in the atmosphere, is also obtained through the information regarding the kinetic 
energy of its molecules, given that the air temperature is the variable that allows us to understand where the heat flow is going. Given this, there is an increasingly greater need to understand how air temperature transients in urban microclimates and topoclimates vary (Araghi et al., 2015; Val et al., 2016).
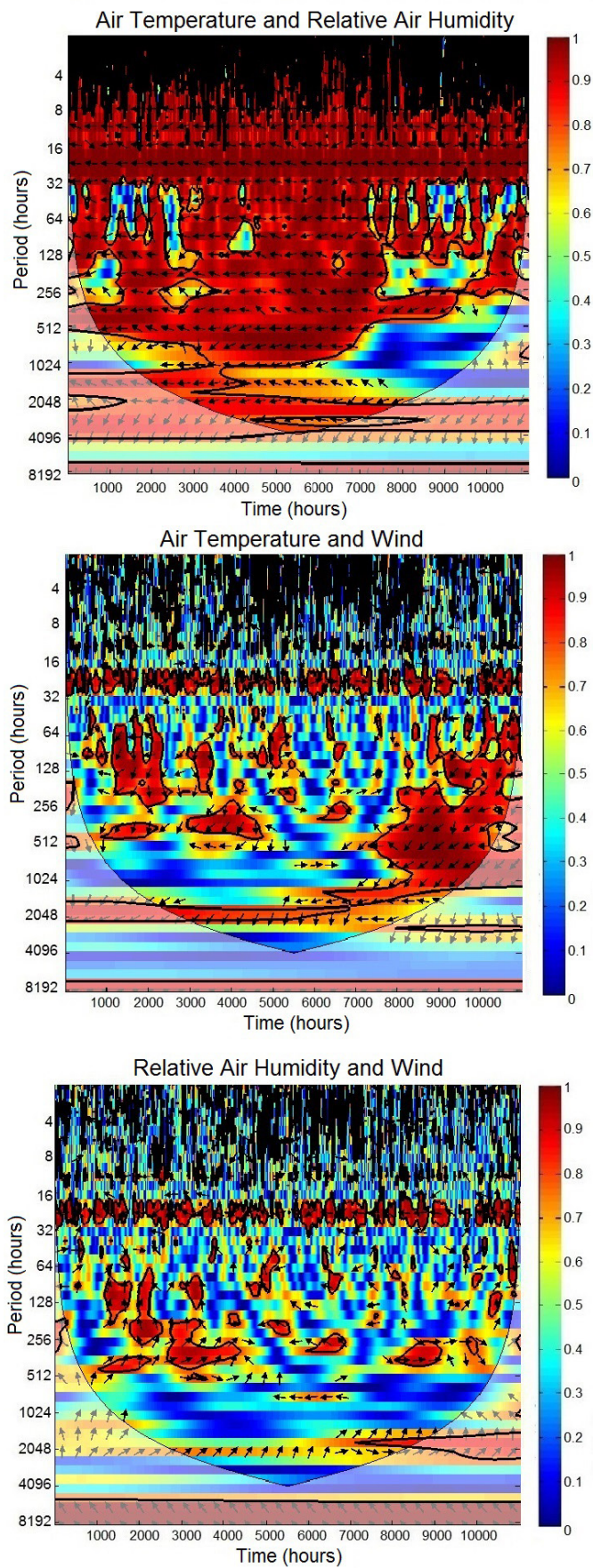

Due to their being extremely influenced by seasonality, the tropical regions of the Brazilian Central-West can use the Wavelet tools at diverse climatic scales, since they demonstrate efficiency in quantitative analysis studies so important for urban development. The Wavelet analyses were conducted together with other microclimatic
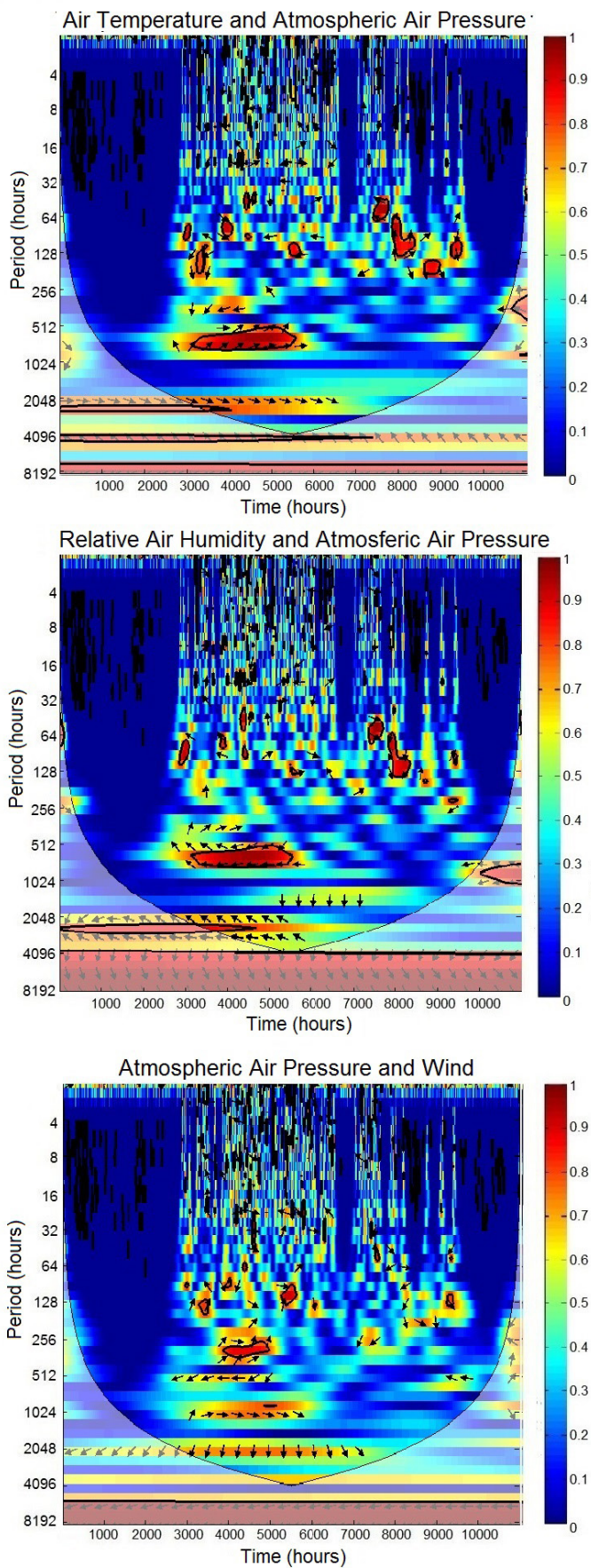

Figure 5. CW for temperature and relative air humidity, wind and atmospheric pressure variables. 
variables not present in this study, such as global solar radiation and precipitation, helping to understand the behavior of the variables studied here.

\section{CONCLUSION}

Physical phenomena are naturally characterized by randomness. Climatic changes that occur in cities over time require increasingly greater representativity of phenomena, for example, influenced from moment to moment. When working with average values for some microclimatic variable, air temperature, for example, the dimensionality of the variable is reduced, losing relevant information and not simply representing an average behavior. When other variables of the same microclimate are treated in the same way, there is a risk of falsified interpretations, modifying the energetic profile and part of the real dynamic of the microclimate.

Air temperature and relative air humidity are considered to be initial environmental thermometers. Allied to wind and atmospheric air pressure variables, a greater representativity of the phenomena is achieved. The wavelet analyses are multi-scale and qualitative, providing real behavioral prospection of an urban topoclimate.

\section{ACKNOWLEDGEMENTS}

Ao Programa de Pós-graduação em Física Ambiental,PPGFA/UFMT, Coordenador Prof. Dr. José de Souza Nogueira e Coordenadora Prof. Dra. Marta Cristina de Albuquerque Nogueira. Instituto Federal de Educação, Ciência e Tecnologia de Mato Grosso, IFMT, Campus Cuiabá, Octayde Jorge da Silva, Departamento e Área de Construção Civil, DACC.

\section{SUBMISSION STATUS}

Received: 25 oct., 2017

Accepted: 23 nov., 2017

\section{CORRESPONDENCE TO}

\section{Angela Rocha}

Rua Profa. Zulmira Canavarros, 95, CEP 78005-200, Cuiabá, MT, Brasil e-mail: angela06.rocha@gmail.com

\section{REFERENCES}

Addison, P. S. The illustrated wavalet transform handbook. 2nd ed. Boca Raton: CRC Press Tylor \& Francis Group. 2017. 446 p.

Araghi A, Mousavi Baygi M, Adamowski J, Malard J, Nalley D, Hasheminia SM. Using wavelet transforms to estimate surface temperature trends and dominant periodicities in Iran based on gridded reanalysis data. Atmospheric Research 2015; 155: 52-72. http://dx.doi.org/10.1016/j. atmosres.2014.11.016.

Cuiabá. Prefeitura Municipal de Cuiabá. Secretaria Municipal de Desenvolvimento Urbano - SMDU. Perfil Socioeconômico de Cuiabá. Vol. 5. Cuiabá; 2012.

Domingues MO, Mendes O, Kaibara MK, Menconi VE, Bernardes E. Explorando a transformada wavelet contínua. Revista Brasileira de Ensino de Física 2016; 38(3): 1-19. http://dx.doi.org/10.1590/1806-9126-RBEF-2016-0019.

Ehlers RS. Análise de Séries Temporais. 2009. (Curso de Séries Temporais)

Feng Y., Liang C. Developing a termal atlas for climateresponsive urban design based on empirical modeling and urban morphological analysis. Energy and Buildings 2016; 111(1): 120-130.

Frick P, Grossmann A, Tchamitchian P. Wavelet analysis of signals with gaps. Journal of Mathematical Physics 1998; 39(1): 4091-4107. http://dx.doi.org/10.1063/1.532485.

Geissbuehler M, Lasser T. How to display data by color schemes compatible with red-green color perception deficiencies. Optics Express 2013; 21(8): 9862-9874. http://dx.doi.org/10.1364/OE.21.009862. PMid:23609692.

Grinsted A, Moore JCS, Jevrejeva S. Application of the cross wavelet transform and wavelet coherence to geophysical time series. Nonlinear Processes in Geophysics 2004; 11(5/6): 561-566. http://dx.doi.org/10.5194/npg-11-561-2004.

Jevrejeva S, Moore JC, Grinsted A. Influence of the Arctic Oscillation and El Niño-Southern Oscillation (ENSO) on ice conditions in the Baltic Sea: The wavelet approach. Journal of Geophysical Research 2003; 108(D21): 1-11. http://dx.doi.org/10.1029/2003JD003417.

Misiti M, Oppenheim G, Poggi JM. Wavelet Toolbox User's Guide: for use with matlab [online]. Natick: The MathWorks; 2017 [cited 2017 Out 2]. Available from: https://www.ltu. se/cms_fs/1.51590!/wavelet\%20toolbox\%204\%20user's\%20 guide $\% 20$ (larger\%20selection).pdf

Oke TR. Initial guidance to obtain representative meteorological observations at urban sites. Geneva: World Meteorological Organization; 2006.

Peng J, Zhao S, Liu Y, Tian L. Identifying the urbanrural fringe using wavelet transform and kernel density estimation: A case study in Beijing City. Environmental 
Modelling \& Software 2016; 83(1): 286-302. http://dx.doi. org/10.1016/j.envsoft.2016.06.007.

Torrence C, Compo YGP. A practical guide to Wavelet analysis. Bulletin of the American Meteorological Society 1998; 79(1): 61-78. http://dx.doi.org/10.1175/15200477(1998)079<0061:APGTWA>2.0.CO;2.

Torrence C, Webster PJ. Interdecadal changes in the Ensomonsoon System. Journal of Climate 1999; 12(8): 2679-2690. http://dx.doi.org/10.1175/1520-0442(1999)012<2679:IC ITEM>2.0.CO;2.
Val J, Pino R, Navarro E, Chinarro D. Addressing the local aspects of global change impacts on stream metabolism using frequency analysis tools. The Science of the Total Environment 2016; 569-570: 798-814. http://dx.doi. org/10.1016/j.scitotenv.2016.06.178. PMid:27392334.

Vilani MT, Sanches L. Análise de Fourier e Wavelets aplicada à temperatura do ar em diferentes tipologias de ocupação. Revista Brasileira de Engenharia Agrícola e Ambiental 2013; 17(12): 1340-1346. http://dx.doi. org/10.1590/S1415-43662013001200013. 